\title{
Short communication: Effects of electrochemically activated drinking water on bovine milk production and composition, including chlorate, perchlorate, and fatty acid profile
}

\author{
Einar Vargas-Bello-Pérez, ${ }^{1 *}$ ๑ Rajan Dhakal, ${ }^{1}$ Mette O. Nielsen, ${ }^{1}$ ๑ Lilia Ahrné, ${ }^{2}$ (C) and Hanne H. Hansen ${ }^{1}$ \\ ${ }^{1}$ Department of Veterinary and Animal Sciences, Faculty of Health and Medical Sciences, University of Copenhagen, Grønnegårdsvej 3, \\ DK-1870 Frederiksberg C, Denmark \\ ${ }^{2}$ Department of Food Science, Faculty of Science, University of Copenhagen, Rolighedsvej 26, DK-1958, Frederiksberg C, Denmark
}

\section{ABSTRACT}

The objective of this study was to assess the effects of electrochemically activated drinking water (ECW) on milk chlorate, milk perchlorate, milk iodine, milk composition, milk fatty acid profile, and overall performance of dairy cows. Ten Red Danish cows in mid-lactation (203 $\pm 31 \mathrm{~d}$ in milk; average $\pm \mathrm{SD})$ were chosen from these 2 groups for intensive sampling. The treated group drank water with $4 \mathrm{ppm}$ of ECW $(29 \mathrm{mg} / \mathrm{L}$ of chlorate of Neuthox, Danish Clean Water A/S, Sønderborg, Denmark). The treatment lasted 60 consecutive days, with milk and water sampling on $\mathrm{d} 0,30$, and 60. Additionally, milk samples from both the control group and treated group were taken on d 90 to assess if any carry-over effect was present. Interactions between period and milk yield and somatic cell for the full group and period and milk fat content and milk urea nitrogen in the selected animals occurred. Milk yield was not significantly affected by treatments. Milk fat, milk fatty acid profile, chlorate, perchlorate, and iodine contents were not significantly different between treatments. Milk urea increased, whereas $\beta$-hydroxybutyrate and somatic cell count decreased significantly in the treated groups. Results showed that at a dosing of $4 \mathrm{ppm}$ of ECW, both chlorate and perchlorate concentrations in milk $(<0.002 \mathrm{mg} / \mathrm{kg})$ were low, and no deleterious effects on milk production or milk chemical composition were observed. These data can be of use when assessing the effects of ECW on milk and milk powder chlorate and perchlorate levels and provide a context for assessing the potential for influencing human health under the conditions prevailing on a commercial dairy farm. Key words: chlorinated water, fatty acids, milk quality, chlorate, iodine

Received August 28, 2019.

Accepted October 20, 2019.

*Corresponding author: evargasb@sund.ku.dk

\section{Short Communication}

Water is essential for health and performance in dairy herds (NRC, 2001). Despite the attention paid to other nutrients, the quantity and quality of water has not been sufficiently considered by researchers (Beede, 2012). Furthermore, farmers often disregard water quality by prioritizing other aspects of cattle production, thus failing to consider it as a possible source of disease and low herd performance. Chlorine has been used for water sanitization (Cheswick et al., 2019). However, chlorate (McCarthy et al., 2018) and other chlorine-derived residues (perchlorate; Capuco et al., 2005) have become a growing concern within the dairy, food, and beverage industries in recent years. In humans, consumption of inorganic chlorine derivatives has been related to hematotoxic and nephrotoxic effects and inhibition of thyroid function (EFSA, 2015). In dairy cows, increases in perchlorate intake can reduce iodine in the thyroid gland and consequently affect the thyroid hormone during pregnancy and lactation (Capuco et al., 2005).

For dairy products, the entry points for chlorate lie both at the primary producer (on-farm practices: drinking water) and at the processing level (processing practices, dilution), which are linked to chlorinated water usage, sanitation practices, or both (McCarthy et al., 2018). Water usage, in all aspects of dairy production, remains a critical entry point of chlorate into the supply chain, thus it is necessary to understand how sanitation of water itself influences this risk of cross-contamination into the dairy supply chain. Electrochemically activated water $(\mathbf{E C W})$ can be used for the prevention and control of microorganism and it is feasible to use because it is relatively easy to produce continuously through electrolysis using commercial equipment (Koide et al., 2011).

Until now, no research has been published on the occurrence of chlorates in foods of ruminant origin when animals are fed with ECW. Therefore, the objective 
of this study was to assess the effects of ECW on milk chlorate, milk perchlorate, milk iodine, milk composition, milk fatty acid (FA) profile, and overall performance of dairy cows.

The experiment was performed at Assendrup Hovedgård (Haslev, Denmark). Two groups of Red Danish cows (61 cows per group) were assigned to 2 treatments: control (no ECW in their drinking water) and ECW (with ECW in their drinking water). The ECW group drank water with a dosage of $4 \mathrm{ppm}$ of Neuthox (29 mg/L of chlorate; Danish Clean Water A/S, Sønderborg, Denmark), which is an ECW additive based on hypochloric acid $(\mathrm{HOCl})$. The ECW was dosed into the drinking water for 60 consecutive days. Monthly milk yield and SCC from both groups were analyzed. To analyze chemical composition of milk and FA profile, a subset of 10 cows (5 cows per group) in their second parity in mid-lactation $(203 \pm 31 \mathrm{~d}$ in milk) were selected based on milk yield $(35 \pm 4 \mathrm{~kg} / \mathrm{d})$. Milk and water samples were collected in different experimental periods: at the beginning of the study $(0 \mathrm{~d}) 30$, and 60 d. Additionally, milk and water samples from both the control and ECW were taken on d 90 (30 d after cessation of any water treatment) to assess if any carryover effects were present.

Animals received the same partial mixed ration ad libitum based on maize and grass silages supplemented by concentrate in the milking robots according to their daily milk yield. The overall forage to concentrate ratio of the diet was 66:34. Animals were fed to fulfill the nutritional requirements for lactating cows based on daily consumption of $23.5 \mathrm{~kg}$ of DM according to the Nordic Feed Evaluation System (NorFor; Volden, 2011). Information about milk yield was extracted from the Danish Dairy Management System (SEGES, Landbrug \& Fødevarer, Denmark). Cows were milked with a Lely automatic milking system (Lely, Maassluis, the Netherlands).

On each milk sampling date at approximately 1100 $\mathrm{h}$, cows were fetched to be milked. At the end of that milking, samples were collected using an external pipeline from each milking robot $(250 \mathrm{~mL}$ per cow per date). Samples were analyzed at a certified laboratory (Eurofins, Vejen, Denmark). Contents of fat, protein lactose, urea, acetone, and BHB were measured by Fourier transform infrared spectroscopy. Somatic cell counts were analyzed by flow cytometry. Chlorate and perchlorate were analyzed by liquid chromatography tandem-mass spectrometry (LC-MS/MS). Iodine was analyzed by inductively coupled plasma MS. Milk FA profile was analyzed using a MilkoScan FT+/FT6000 (Foss, Hillerød, Denmark) equipped with special software (Foss Application Note 64, Foss) for predicting
7 FA fractions, namely SFA, MUFA, PUFA, shortchain FA, medium-chain FA (MCFA), long-chain FA (LCFA), and trans FA, as well as 4 individual FA, namely C14:0, C16:0, C18:0, and C18:1.

Five liters of milk was taken on d 60 and 90 from each experimental group. Milk samples were frozen at $-20^{\circ} \mathrm{C}$. These samples were used to produce milk powder at the Dairy Pilot Plant at the University of Copenhagen. The milk powder was produced by spray drying using a Silverson Mixer and GEA Mobil Minor Spray Dryer Type MM-I (Søborg, Denmark) run in a co-current spray nozzle. Before spray drying, the 5-L frozen container of milk was thawed for $24 \mathrm{~h}$ in a refrigerator at $4^{\circ} \mathrm{C}$ followed by heating in a warm water bath until the temperature of the milk had reached 15 to $20^{\circ} \mathrm{C}$. After heating, the milk was homogenized with a Silverson Mixer at a low speed for $30 \mathrm{~s}$ and fed to the spray dryer, keeping the milk temperature at $20^{\circ} \mathrm{C}$ during agitation. The spray drying was performed at an inlet temperature of $190^{\circ} \mathrm{C}$ and outlet temperature of $70^{\circ} \mathrm{C}$. Flow of inlet air was around $40 \mathrm{~kg} / \mathrm{h}$ and spraying air pressure was $1,500 \mathrm{kPa}$. During spray drying, feed flow was regulated to keep $70^{\circ} \mathrm{C}$ as outlet temperature. The total drying time for $5 \mathrm{~L}$ of milk was between 4 and $5 \mathrm{~h}$. Four milk powder samples (150 g per sample) were analyzed at Eurofins Milk Testing Denmark A/S for contents of chlorate and perchlorate by LC-MS/MS.

Water samples were analyzed for chlorate and perchlorate by LC-MS/MS (Eurofins Miljø, Denmark). Water samples $(250 \mathrm{~mL}$ per sampling site per sampling date) were taken with a sterile syringe. Water samples were placed into plastic sterile containers covered with aluminum foil to protect samples from the potentially harmful effects of exposure to UV radiation. Water samples were taken from 5 different sites: drinking troughs ( $\mathrm{n}=2$ per sampling date; with or without dosing), water pipelines ( $\mathrm{n}=2$ per sampling date; with or without dosing), and tap water $(\mathrm{n}=1$ per sampling date) from the farm. Water valves from pipelines and tap water were opened for $15 \mathrm{~min}$ before sampling to ensure a representative sample.

Data were analyzed using $\mathrm{R}$ 3.5.1 ( $\mathrm{R}$ Core Team, 2018). A linear mixed model (Pinheiro et al., 2018) was used for data analysis. For each measurement, the following model was used:

$$
\mathrm{Y}=\text { date } \times \text { treatment }+ \text { random }(\text { cow })+\text { error, }
$$

where date $=0,30,60$, and $90 \mathrm{~d}$; and treatment $=$ control and ECW. Experimental period, treatment, and interaction between experimental period and treatment were considered as fixed effects and cow as a random effect. Normality of the model was assessed using 
quantile-quantile plots of the residuals of the full and reduced models. Analysis of variance was used to assess the significance of the predictor of the model. Insignificant terms were eliminated from the model through model reduction. Significance was considered at $P<$ 0.05. All the results are expressed as least squares means with standard error of the mean.

Milk yield was not significantly affected by treatments for the entire group (61 cows per treatment) or the subset of selected animals ( 5 cows per treatment), but decreased throughout the experimental period. The decrease was not the same for both and this resulted in a significant interaction (Figure 1). This was expected due to advancing lactation stage (Table 1). Except for milk urea (increased in ECW cows), milk composition was not significantly affected by treatments; however, the urea content fluctuated in the ECW group, resulting in a significant interaction. A numerical decrease in milk protein contents was also observed in cows provided ECW. Milk urea $\mathrm{N}$ reflects the blood urea $\mathrm{N}$ content, and thus, MUN is often used as an index of $\mathrm{N}$ utilization efficiency in lactating cows (Broderick and Clayton, 1997). However, additional studies with higher numbers of cows would be needed to establish whether the elevated MUN in ECW could be due to a reduced protein and energy supply to rumen microbes (Gross and Bruckmaier, 2019).

Contents of milk BHB were significantly lower in the ECW group. $\beta$-Hydroxybutyrate is used as an indicator for the metabolic rate in cows, with a low value indicating a high level of energy metabolism (Gross and Bruckmaier, 2019) or a change in rumen fermentation patterns resulting in higher production of butyrate relative to acetate and propionate. In this study, it is possible that cows treated with ECW were more energy efficient. The significant interactions observed between fat $\%$, MUN, acetone, and iodine point at changes in the rumen fermentation patterns. Additional experiments are needed to explain such effects of ECW at the rumen level and on rumen microbial populations.

Milk FA profiles, chlorate, and perchlorate levels were not different between treatments. However, milk SCC were significantly reduced in the subset of selected cows with ECW, but this was not the case for the whole groups (61 cows per treatment). This discrepancy may be explained due to the difference in the number of animals and the huge variation normally seen in SCC. Despite the fact that the milk FA profile showed no differences between treatments (Table 2), total PUFA and total trans FA changed significantly over time. This further indicates that there may have been effects of the ECW on rumen fermentation patterns or bacteria, or both, which are responsible for the formation of these FA mainly through rumen biohydrogenation
(Vargas-Bello-Pérez et al., 2016; Vasta et al., 2019). Further research is advised to confirm the long-term effects of ECW on the rumen microbiome.

Milk iodine content was not affected by ECW, and this finding is very important for dairy production because iodine and thyroid hormones play an important role in general body metabolism and mammary gland function (Capuco et al., 2005). A reduction of iodine by the ECW will reduce thyroid hormone activity. For example, thyroid hormone administration can increase milk production in dairy cows, which is because triiodothyronine potentiates the activity of lactogenic and
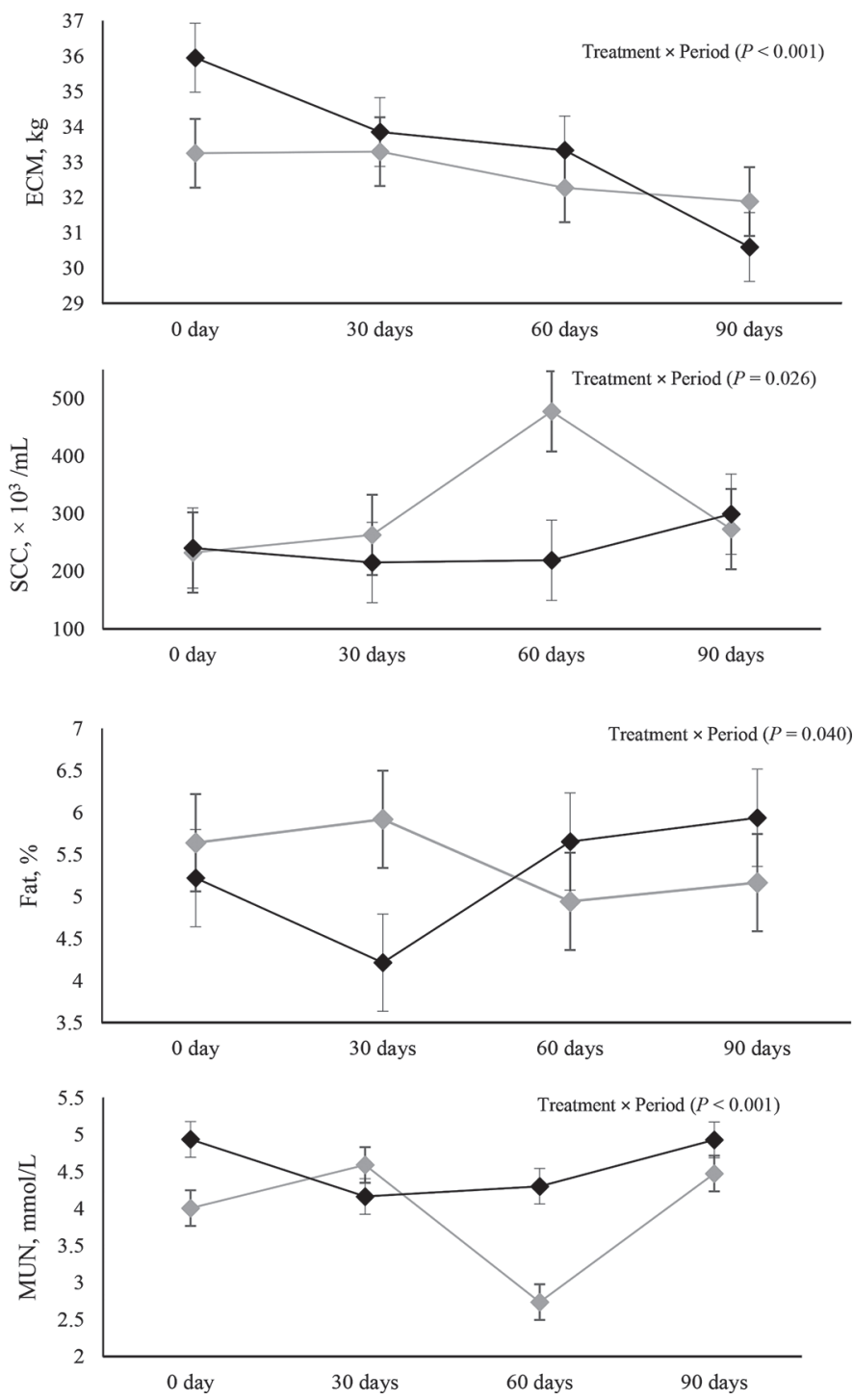

Figure 1. Interactions between treatment (control vs. electrochemically activated water) and experimental periods for milk composition and milk metabolites. Gray diamonds are the control, and black diamonds are the electrochemically activated water. The ECM and SCC are based on data from 61 cows per treatment. Fat and MUN are based on data from 5 cows per treatment. Error bars denote SEM. 
Table 1. Milk production, milk composition, and milk metabolites from cows fed with or without electrochemically activated water (ECW; n $=5$ cows per treatment unless otherwise stated $)^{1}$

\begin{tabular}{|c|c|c|c|c|c|c|}
\hline \multirow[b]{2}{*}{ Parameter } & \multicolumn{2}{|c|}{ Treatment } & \multirow[b]{2}{*}{ SEM } & \multicolumn{3}{|c|}{$P$-value } \\
\hline & Control & ECW & & Treatment $(\mathrm{T})$ & Period $(\mathrm{P})$ & $\mathrm{T} \times \mathrm{P}$ \\
\hline Milk yield, $\mathrm{kg}$ of ECM & 30.4 & 32.7 & 1.50 & NS & $<0.001$ & NS \\
\hline \multicolumn{7}{|l|}{ Milk composition } \\
\hline SCC,$\times 10^{3} / \mathrm{mL}$ (61 cows per treatment) & 311.78 & 243.59 & 49.98 & NS & NS & 0.026 \\
\hline $\mathrm{SCC}, \times 10^{3} / \mathrm{mL}$ & 547.75 & 138.40 & 137.24 & 0.01 & NS & NS \\
\hline Protein, \% & 4.06 & 3.88 & 0.07 & NS & 0.06 & NS \\
\hline MUN, mmol/L & 3.95 & 4.59 & 0.17 & 0.02 & $<0.001$ & $<0.001$ \\
\hline \multicolumn{7}{|l|}{ Milk metabolite } \\
\hline Acetone, mmol/L & 0.06 & 0.05 & 0.01 & NS & $<0.001$ & 0.083 \\
\hline $\mathrm{BHB}, \mathrm{mmol} / \mathrm{L}$ & 0.11 & 0.04 & 0.02 & 0.03 & 0.01 & NS \\
\hline Iodine, $\mu \mathrm{g} / \mathrm{kg}$ & 173.10 & 178.40 & 22.04 & NS & $<0.001$ & NS \\
\hline Chlorate, $\mu \mathrm{g} / \mathrm{kg}$ & $<0.002$ & $<0.002$ & $<0.002$ & - & - & - \\
\hline
\end{tabular}

${ }^{1}$ The ECM was calculated according to the Nordic feed evaluation system (NorFor; Volden, 2011).

galactopoietic hormones (Bhattacharjee and Vonderhaar, 1984).

Significant interactions between treatments (control vs. ECW) and experimental periods in yield (ECM), SCC, milk fat percentage, and MUN were observed (Figure 1). Milk yield and SCC from the all animals (61 cows per treatment) had significant interactions between treatment and periods. Milk yield from all cows started at different basal points but later decreased in both treatments. This was expected due to advanced stage of lactation. With regard to SCC from all cows, SCC were the same at the onset of the experiment, but on d 60 the control group showed elevated SCC compared with ECW and this points to a possible effect of ECW on SCC. It is noteworthy to mention that ECW animals remained below $300 \times 10^{3} / \mathrm{mL} \mathrm{SCC} \mathrm{over}$ the experiment.

Milk fat contents were similar in both treatments at the beginning of the study and on d 30, milk fat was de- creased by ECW, then on d 60 both treatments reached similar milk fat contents and were likewise similar on d 90. Milk urea $\mathrm{N}$ was different at d 0 and 60 with the highest contents from ECW. It appears that the ECW disrupted the rumen balance, most likely at the rumen level, and thereby affected the milk fat production and protein metabolism (as shown in MUN); however, that remains unclear. Further research is advised to corroborate such effects. The iodine content in milk decreased from the beginning of the study until d 90 in both ECW and the control with no interaction with period. This may be attributed to the advancing stage of lactation with decreasing metabolic activity of the mammary gland.

Significant interactions between treatments and experimental periods were found in C16:0, total SFA, total MCFA, and total LCFA (Figure 2). These are supporting results showing that ECW had a short-term effect at rumen level, especially during the first $30 \mathrm{~d}$ of

Table 2. Individual fatty acids and groups of fatty acids in milk from cows fed with or without electrochemically activated water $(\mathrm{ECW})^{1}$

\begin{tabular}{|c|c|c|c|c|c|c|}
\hline \multirow[b]{2}{*}{ Fatty acid, g/100 g } & \multicolumn{2}{|c|}{ Treatment } & \multirow[b]{2}{*}{ SEM } & \multicolumn{3}{|c|}{$P$-value } \\
\hline & $\begin{array}{l}\text { Control } \\
(\mathrm{n}=5)\end{array}$ & $\begin{array}{c}\text { ECW } \\
(\mathrm{n}=5)\end{array}$ & & Treatment $(\mathrm{T})$ & Period $(\mathrm{P})$ & $\mathrm{T} \times \mathrm{P}$ \\
\hline C14:0 & 0.66 & 0.62 & 0.05 & NS & NS & NS \\
\hline $\mathrm{C} 16: 0$ & 1.74 & 1.72 & 0.13 & NS & NS & 0.02 \\
\hline C18:0 & 1.11 & 1.07 & 0.08 & NS & NS & NS \\
\hline$\Sigma \mathrm{SFA}$ & 3.73 & 3.58 & 0.29 & NS & NS & 0.04 \\
\hline$\Sigma$ Short-chain fatty acids (C6:0-C10:0) & 0.54 & 0.54 & 0.06 & NS & NS & NS \\
\hline$\Sigma$ Medium-chain fatty acids (C12:0-C14:0) & 2.69 & 2.65 & 0.19 & NS & NS & 0.02 \\
\hline$\Sigma$ Long-chain fatty acids & 1.89 & 1.82 & 0.14 & NS & NS & 0.04 \\
\hline$\Sigma$ trans fatty acids & 0.14 & 0.13 & 0.02 & NS & $<0.001$ & NS \\
\hline
\end{tabular}

${ }^{1}$ Values are means and pooled $\mathrm{SEM}=5$ cows per treatment. 
treatment. It is known that half of $\mathrm{C} 16: 0$ contents in milk come from the de novo synthesis and also MCFA originate during rumen fermentation (Vasta et al., 2019). In addition, it should be noted that C16:0 is one of the main SFA found in milk (Vargas-Bello-Pérez et al., 2017) and this group of FA followed the same trend over the time.

In the milk powder samples, contents of chlorate remained below $0.01 \mathrm{mg} / \mathrm{kg}$ and perchlorate levels were below $0.015 \mathrm{mg} / \mathrm{kg}$ (Table 3 ). Those levels are relatively low compared with EFSA guidelines (EFSA,
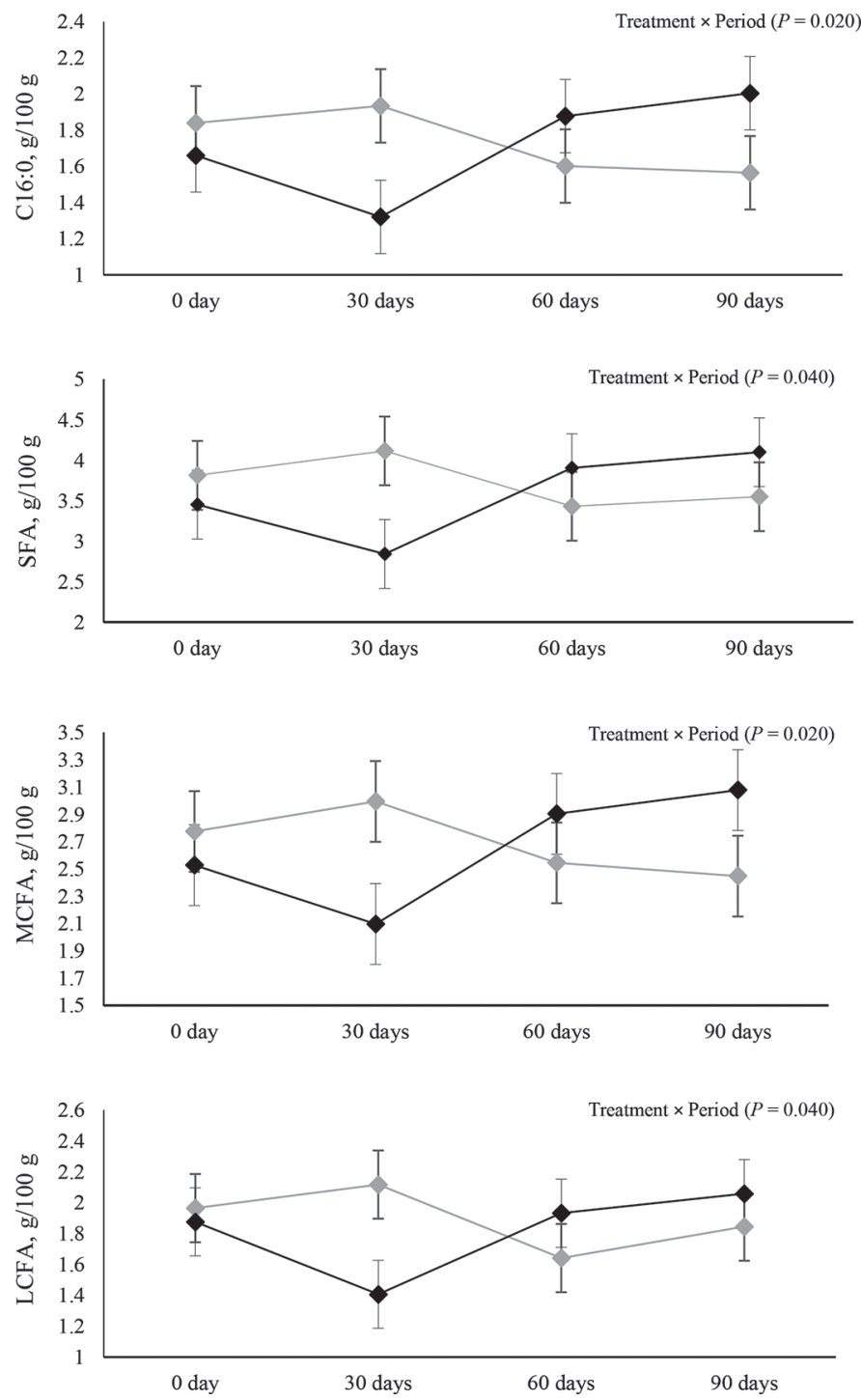

Figure 2. Interactions between treatment (control vs. electrochemically activated water) and experimental periods for milk fatty acid profile. SFA $=\Sigma$ saturated fatty acids; $\mathrm{MCFA}=\Sigma$ medium-chain fatty acids (C12:0-C14:0); LCFA $=\Sigma$ long-chain fatty acids. Gray diamonds are the control, and black diamonds are the electrochemically activated water. Data are based on 5 cows per treatment. Error bars denote SEM.
Table 3. Chlorate and perchlorate contents in milk powder samples

\begin{tabular}{lcc}
\hline Sample & $\begin{array}{c}\text { Chlorate, } \\
\mathrm{mg} / \mathrm{kg}\end{array}$ & $\begin{array}{c}\text { Perchlorate, } \\
\mathrm{mg} / \mathrm{kg}\end{array}$ \\
\hline Control group at d 60 & $<0.01$ & 0.006 \\
Control group at d 90 & $<0.01$ & 0.007 \\
ECW $^{1}$ group at d 60 & $<0.01$ & 0.011 \\
ECW group at d 90 & $<0.01$ & 0.015 \\
\hline
\end{tabular}

${ }^{1} \mathrm{ECW}=$ electrochemically activated water.

2014, 2015). However, more samples will be needed for a more robust and conclusive result. It is important to note that the maximum residue limit allowed for chlorate [regulation (EC) no. 396/2005] in all foodstuffs and drinking water is $0.1 \mathrm{mg} / \mathrm{kg}$ (EFSA, 2015).

To ensure the dosing of ECW, chlorate and perchlorate contents in different sites from the farm water supply were monitored in all experimental periods as shown in Table 4. There were some fluctuations in the pipeline and drinking troughs with ECW. An automatic system delivered ECW to the water supply in pulses according to water flow. Therefore, it is possible that the ECW dose was given during the 15 min of water flow on $\mathrm{d} 30$ and 60 . The pipeline values reflect the differences between treated and untreated water entering the troughs, whereas trough values reflect what the cows could drink.

The low concentrations of chlorate and perchlorate found in milk, given an intake of approximately $100 \mathrm{~L}$ of water per cow per day, suggest that these substances are largely metabolized within the gastrointestinal tract, and not absorbed in significant amounts. This agrees with Capuco et al. (2005), who discussed that the rumen of the dairy cow might serve as a biological filter reducing the transfer of perchlorate into milk as well as in urinary and fecal outputs. Over a 5-wk period, they continuously rumen-infused cows with doses up to 40 mg of perchlorate (supplied as $\mathrm{NaClO}_{4}$ ) and reported that up to $80 \%$ of dietary perchlorate was metabolized, most likely in the rumen, which would provide cattle with a degree of adaptation to perchlorate.

Overall, at a dosing of $4 \mathrm{ppm}$ of ECW, both chlorate and perchlorate concentrations in milk $(<0.002 \mathrm{mg} /$ $\mathrm{kg})$ and milk powder $(<0.01 \mathrm{mg} / \mathrm{kg})$ were low, and no deleterious effects on milk production or milk chemical composition were observed. Our data can be of use when assessing the effects of an ECW additive on milk chlorate and perchlorate levels and provide a context for assessing the potential for influencing human health at least under the conditions prevailing on a commercial dairy farm.

From an animal research perspective, further studies should consider the following: (1) ECW seems to have positive effects by reducing SCC, but a larger study 
Table 4. Chlorate and perchlorate contents in different sites from the water supply of the farm

\begin{tabular}{|c|c|c|c|}
\hline Location & Period, d & $\begin{array}{c}\text { Chlorate, } \\
\mathrm{mg} / \mathrm{L}\end{array}$ & $\begin{array}{c}\text { Perchlorate, } \\
\mathrm{mg} / \mathrm{L}\end{array}$ \\
\hline$\overline{\text { Pipeline without ECW }}{ }^{1}$ & & $<2$ & $<0.5$ \\
\hline Pipeline with ECW & & $<2$ & $<0.5$ \\
\hline Tap water & 0 & $<2$ & $<0.5$ \\
\hline Drinking troughs without ECW & & $<2$ & $<0.5$ \\
\hline Drinking troughs with ECW & & $<2$ & $<0.5$ \\
\hline Pipeline without ECW & & $<2$ & $<0.5$ \\
\hline Pipeline with ECW & & 190 & $<0.5$ \\
\hline Tap water & 30 & $<2$ & $<0.5$ \\
\hline Drinking troughs without ECW & & $<2$ & $<0.5$ \\
\hline Drinking troughs with ECW & & 280 & $<0.5$ \\
\hline Pipeline without ECW & & $<2$ & $<0.5$ \\
\hline Pipeline with ECW & & 490 & $<0.5$ \\
\hline Tap water & 60 & $<2$ & $<0.5$ \\
\hline Drinking troughs without ECW & & $<2$ & $<0.5$ \\
\hline Drinking troughs with ECW & & 330 & $<0.5$ \\
\hline Pipeline without ECW & & $<2$ & $<0.5$ \\
\hline Pipeline with ECW & & $<2$ & $<0.5$ \\
\hline Tap water & 90 & $<2$ & $<0.5$ \\
\hline Drinking troughs without ECW & & $<2$ & $<0.5$ \\
\hline Drinking troughs with ECW & & $<2$ & $<0.5$ \\
\hline
\end{tabular}

${ }^{1} \mathrm{ECW}=$ electrochemically activated water.

with more animals and longer experimental periods will be advised to confirm any beneficial effects of chlorinated drinking water on udder health. (2) Analyses of chlorate, perchlorate, and iodine in blood, urine, and feces in addition to milk and milk powder should be considered. Determining iodine contents in body fluids and excretions as well as analyzing total contents of blood thyroxine and triiodothyronine will help to ensure that chlorinated drinking water does not have adverse effects on thyroid hormones, which are crucial for general body metabolism and mammary gland function.

From a food science perspective, it is important to note that while the European Commission will set a legal maximum residue limit for chlorate in milk and dairy products, it is expected that key players in the milk processing industry and dairy ingredients, in particular the infant formula manufacturers, will set their own more stringent levels and those are likely to remain at $0.01 \mathrm{mg} / \mathrm{kg}$. It will be therefore crucial for further studies to consider increasing the number of milk powder samples to be able to analyze the effects of chlorinated drinking water on this food and other milkderived products under commercial farm conditions.

\section{ACKNOWLEDGMENTS}

We thank Kjeld Christensen from Assendrup Hovedgård for the animal facilities and assistance in obtaining research data. We also thank Lasse Sembach (University of Copenhagen, Denmark), Maria Katrine Rasmussen (Zealand Academy of Technologies and
Business, Denmark), Khulan Bayarsaikhan (Ecole d'Ingénieurs de PURPAN, France), and Rikke Prahl (Denmark) for their assistance during the collection of milk and water samples and Sylvain Barjon (University of Copenhagen, Denmark) for the milk processing. The authors have not stated any conflicts of interest.

\section{REFERENCES}

Beede, D. K. 2012. What will our ruminants drink? Anim. Front. 2:36-43. https://doi.org/10.2527/af.2012-0040.

Bhattacharjee, M., and B. K. Vonderhaar. 1984. Thyroid hormones enhance the synthesis and secretion of $\alpha$-lactalbumin by mouse mammary tissue in vitro. Endocrinology 115:1070-1077. https:// doi.org/10.1210/endo-115-3-1070.

Broderick, G. A., and M. K. Clayton. 1997. A statistical evaluation of animal and nutritional factors influencing concentrations of milk urea nitrogen. J. Dairy Sci. 80:2964-2971. https://doi.org/10 .3168/jds.S0022-0302(97)76262-3.

Capuco, A. V., C. P. Rice, R. L. Baldwin, D. D. Bannerman, M. J. Paape, W. R. Hare, A. C. W. Kauf, G. W. McCarty, C. J. Hapeman, A. M. Sadeghi, J. L. Starr, L. L. McConnell, and C. P. Van Tassell. 2005. Fate of dietary perchlorate in lactating dairy cows: Relevance to animal health and levels in the milk supply. Proc. Natl. Acad. Sci. USA 102:16152-16157. https://doi.org/10.1073/ pnas.0508337102.

Cheswick, R., E. Cartmell, S. Lee, A. Upton, P. Weir, G. Moore, A. Nocker, B. Jefferson, and P. Jarvis. 2019. Comparing flow cytometry with culture-based methods or microbial monitoring and as a diagnostic tool for assessing drinking water treatment processes. Environ. Int. 130:104893. https://doi.org/10.1016/j.envint.2019.06 .003 .

EFSA. 2014. Panel on Contaminants in the Food Chain (CONTAM). Scientific opinion on the risks to public health related to the presence of perchlorate in food, in particular fruits and vegetables. EFSA J. 12:3869. https://doi.org/10.2903/j.efsa.2014.3869.

EFSA. 2015. Panel on Contaminants in the Food Chain (CONTAM) Risks for public health related to the presence of chlorate in food. EFSA J. 13:4135. https://doi.org/10.2903/j.efsa.2015.4135. 
Gross, J. J., and R. M. Bruckmaier. 2019. Review: Metabolic challenges in lactating dairy cows and their assessment via established and novel indicators in milk. Animal 13(S1):s75-s81. https://doi .org/10.1017/S175173111800349X.

Koide, S., D. Shitanda, M. Note, and W. Cao. 2011. Effects of mildly heated, slightly acidic electrolyzed water on the disinfection and physicochemical properties of sliced carrot. Food Control 22:452456. https://doi.org/10.1016/j.foodcont.2010.09.025.

McCarthy, W. P., T. F. O'Callaghan, M. Danahar, D. Gleeson, C. O'Connor, M. A. Fenelon, and J. T. Tobin. 2018. Chlorate and other oxychlorine contaminants within the dairy supply chain. Compr. Rev. Food Sci. Food Saf. 17:1561-1575. https://doi.org/10 .1111/1541-4337.12393.

NRC. 2001. Water Requirements in Nutrient Requirements of Dairy Cattle. 7th rev. ed. National Academy Press, Washington, DC.

Pinheiro, J., D. Bates, S. DebRoy, D. Sarkar, and 2018 R Core Team. 2018. Nlme: Linear and Nonlinear Mixed Effects Models. R package version $3.1-137$.

R Core Team. 2018. R: A language and environment for statistical computing. R Foundation for Statistical Computing, Vienna, Austria. https://www.R-project.org/.

Vargas-Bello-Pérez, E., N. Cancino-Padilla, J. Romero, and P. C. Garnsworthy. 2016. Quantitative analysis of ruminal bacterial populations involved in lipid metabolism in dairy cows fed differ- ent vegetable oils. Animal 10:1821-1828. https://doi.org/10.1017/ S1751731116000756.

Vargas-Bello-Pérez, E., P. Toro-Mujica, D. Enriquez-Hidalgo, M. A. Fellenberg, and P. Gomez-Cortes. 2017. Short communication: Discrimination between retail bovine milks with different fat contents using chemometrics and fatty acid profiling. J. Dairy Sci. 100:4253-4257. https://doi.org/10.3168/jds.2016-12393.

Vasta, V., M. Daghio, A. Cappucci, A. Buccioni, A. Serra, C. Viti, and M. Mele. 2019. Invited review: Plant polyphenols and rumen microbiota responsible for fatty acid biohydrogenation, fiber digestion, and methane emission: Experimental evidence and methodological approaches. J. Dairy Sci. 102:3781-3804. https://doi.org/ 10.3168/jds.2018-14985.

Volden, H. 2011. NorFor - The Nordic feed evaluation system. EAAP Scientific Series. Wageningen Academic Publishers, Wageningen, the Netherlands.

\section{ORCIDS}

Einar Vargas-Bello-Pérez @ https://orcid.org/0000-0001-7105-5752

Mette O. Nielsen ㄴ) https://orcid.org/0000-0002-8364-835X

Lilia Ahrné $\odot$ https://orcid.org/0000-0003-4360-8684 